\title{
Sexually transmitted diseases in modern China: a historical survey
}

\author{
Frank Dikötter
}

\begin{abstract}
This paper points to the congruence between political and social variables and the epidemiology of sexually transmitted diseases (STDs) in modern China. STDs became a major health problem after the fall of the empire in 1911 and were only reluctantly addressed by a weak nationalist government during the 1930s. During the 1950s and 60s, the communist regime brought STDs under control, but problems have reappeared since reforms were implemented during the 1980 s. Cultural values and social attitudes have also structured medical responses to venereal disease. From the reform movements between the two World Wars to the more recent communist health campaigns, medical theory has often been confused with moral prescription.
\end{abstract}

(Genitourin Med 1993;69:341-345)

Reliable statistics for the history of sexually transmitted diseases (STDs) in modern China still have to be uncovered. The state of historical epidemiology is underdeveloped, and the cultural history of medicine in this country has started only recently. An impressionistic overview based on scattered reports, however, reveals the existence of a congruence between political and social variables and the epidemiology of STDs. Cultural values and social attitudes, moreover, have also structured medical responses to venereal disease.

LATE IMPERIAL CHINA (618-1911)

Medical literature under the Tang dynasty (A.D. 618-907) indicated the existence of types of venereal diseases, in particular certain forms of what would now be called gonorrhoea. Some texts provided detailed descriptions of chronic ulcers of the genitals, stricture of the urethra and symptoms which indicated gonococcal arthritis. None of these infections, however, was recognised as being transmitted by sexual intercourse, although Tang physicians realised that sexual promiscuity encouraged the spread of contagious diseases. Called strangury (linzhuo), gonorrhoea was thought to be limited to penile pain during urination and viscid discharges from the urethra. According to Chinese pathology, it was a benign disease due to an attack of wetness-heat evil on the urinary bladder.

Syphilis is thought to have appeared only at the beginning of the sixteenth century through European contact. In a medical survey of the ravages caused by a skin-disease which had started in Canton, Yu Bian noted syphilitic chancres and prescribed sarsaparilla and quicksilver for relief. ${ }^{1} \mathrm{~A}$ more detailed account of venereal disease was published in 1632 by Chen Sicheng. His Secret Account of Plum Sores (Meichuang bilu) was based on an epidemic which had occurred at the beginning of the 1630s. Most sources of this period referred to the disease as "Cantonese sores" (guangchuang), or "plum-blossom sores" (yangmeichuang), a term which invoked the resemblance of the chancre to a plum-blossom. Although sexual intercourse was thought to be the main cause of infection, the theory of humours explained buboes as a stasis of humid heat and a poisoning of the vital breath. Syphilis, moreover, was not seen as an infection characterised by latent periods. With the natural disappearance of the initial chancre, the disease was generally thought to be cured. Venereal diseases were a nosological category classified as "emptiness of the kidneys" until the introduction of new medical thought systems at the end of the nineteenth century.

Translations of medical texts by foreign missionaries started to appear after the Opium Wars (1839-1842 and 1857-1860), and a Treatise of Syphilis was even published in Chinese by a Christian missionary in $\mathbf{1 8 7 5}$. The presence of foreign physicians in the settlements of the open ports also contributed to the introduction of new medical systems into China. The passage of the Contagious Diseases Act of 1866 in the United Kingdom, for instance, brought concern about the medical consequences of prostitution to the European Settlement in Shanghai. Although the real extent of venereal diseases in this port was never accurately diagnosed, the frequency of eye inflammation of venereal origin was noted. A Report on Prostitution in Shanghai was published in 1871 by the principal health officer, ${ }^{2}$ and the municipal Council started to implement a system of control over prostitution a few years later. These developments, however, had little impact on the indigenous understanding of venereal diseases. Sustained interest in foreign thought systems started only with the reform movement after the defeat of China in the Sino-Japanese War of 1894. Study societies were founded to promote ideas of social reform and institutional renewal: they were the result of indigenous trends of thought which had been critical of

\footnotetext{
St, Russell Square, UK

Frank Dikötter

Accepted for publication 14 January 1993

Department of
History, School of Studies, University of London, Thornhaugh
} 
orthodox Confucianism since the late eighteenth century and were the expression of the new social classes which had flourished through contacts with Western traders. Reform-minded scholars published polemical essays and introduced a range of ideas in science and politics from the West. Medical literature was also translated, particularly after the abolition of the imperial examination system in 1904. The introduction of new knowledge during the 1890s and 1900s was used in reformed medical circles to attack traditional notions of disease. The transmission and pathology of venereal diseases served to discard the unicist theory, which ascribed a single venereal poison to a variety of different symptoms. The theory of infection also gradually replaced the powerful theory of humours, and the genuine pathology of syphilitic infection became better understood. As a contagious disease caused by a spirochete transmitted through sexual intercourse, syphilis could be demonstrated to cause systemic dangers such as cardiovascular ailments, partial paralysis and mental disorders. With the introduction of the concept of latency in the symptomatology of syphilis, the syphilitic chancre, called "hard chancre" (yingxiagan or yingxing xiagan) was differentiated from the chancroid, or genital ulcer called "soft chancre" (ruanxiagan or manxing xiagan), a common infection in parts of China. As in the West till the middle of the nineteenth century, syphilis and gonorrhoea had been hitherto poorly distinguished, and the specificity of both diseases was recognised by reformed physicians during the 1890s. With the acceptance of the gonococcus as a bacterial organism responsible for infection, it also became clear that gonorrhoea could cause a variety of ailments such as dermatitis and arthritis.

\section{REPUBLICAN CHINA (1911-1949)}

The Republic of China (1911-1949), proclaimed after the fall of the Qing empire, was an era of social and political fragmentation. Warlordism and militarism ravaged most of the country until the end of the $1920 \mathrm{~s}$, and Japanese encroachments precipitated a fullfledged war in 1937. The rural areas suffered from oppression, famine, and banditry; the urban centres endured corruption and maladministration. The collapse of the empire was also followed by a phase of expansion of STDs, a phenomenon caused by the relaxation of the registration of public houses, increased social mobility, the geographical distribution of venereal disease by itinerant warlord troops and the general disintegration of traditional standards of behaviour. Ignorance of the nature of venereal diseases, lack of hygiene and poor education further contributed to the rapid diffusion of venereal infections.

The precise incidence of venereal diseases in Republican China remains a matter of conjecture. Measures for the investigation of the sources of infection were implemented after 1949 only, and few hospitals or health depart- ments collected venereal statistics. Although reliable data on the incidence and prevalence of venereal diseases are unavailable, the introduction of serological tests during the $1920 \mathrm{~s}$ in the better equipped hospitals allowed some medical missionaries to reveal the extent of infection. James Maxwell was the first to establish the severe nature of venereal diseases in China. ${ }^{3}$ Lennox's study in 1923, based on 35,000 hospital cases, provided more detailed data; it established that $8,4 \%$ of in-patients and $6,1 \%$ of out-patients were syphilitic, which represented three times the average in the United States. ${ }^{4}$ Another foreign doctor examined 4,000 patients and found that $25 \%$ displayed venereal symptoms. ${ }^{5}$ Although the different statistical methods used by physicians do not allow for any meaningful comparisons, other figures based on hospital statistics also indicate that the incidence of syphilis was very high during the period between the two wars, and typically ranged between 20 and $25 \%$ of patients. ${ }^{6}$ Estimates for the general population have ranged from $5 \%$ to as high as $50 \%$ or $60 \%$. $^{7}$ Herbert Lamson, who summarised most medical findings, believed the problem of venereal diseases to be very important both in a qualitative and in a quantitative manner, ${ }^{8}$ whereas a contemporary observer estimated the total number of infections of syphilis at 20 million for the whole of China at the eve of the Second World War, a conservative figure which should probably be increased by half.

Prostitutes were the main victims of venereal infection. Although public houses were a source of relaxation and recreation for most social classes, rates of infection appeared to be higher in merchants and soldiers. Occupational mobility and regular attendance at brothels were the main reasons for exposure to venereal diseases by these two groups. Soldiers in the Chinese army were not subjected to any physical or serological examinations, but some available statistics reveal high rates. In one case, $21.93 \%$ of a total of 310 soldiers who visited a hospital tested positive on the Kahn blood test, compared with $13.5 \%$ of 420 civilian patients. ${ }^{10}$ Military officers, police agents, domestic servants and craftsmen were the next largest groups; the liberal professions, including clerks and students, were the least infected sectors of the population. The majority of the peasants may have been relatively unaffected by venereal diseases during the first decade of this century, but civil war, migrations and social mobility led to an even epidemiological distribution over the country in the 1930s. Men were the most exposed group, although the extent of female infection was also significant; of 268 cases in one year during the mid1920 s at the Union Medical College for Women in Beijing, 12 patients were prostitutes and the remaining 256 women had contracted venereal disease from their husbands. Ophthalmia neonatorum was common, and babies with syphilitic eruption were often laid aside and left to starve. ${ }^{11}$

A deep psychological stigma was attached 
to venereal infection and influenced therapeutic approaches. Reluctance to seek medical advice and the concealment of symptoms also made it difficult for observers to get a clear picture of the different genitourinary infections which afflicted modern China. Syphilis was undoubtedly the most serious of the STDs, but it was rarely diagnosed as a primary lesion. Foreign observers believed the combined effect of syphilis and lowered physical vitality to be the cause for the frequency of phagadenic ulceration. Gummatous lesions were common on skins and scalp and also attacked the nasal and adjacent bones; destruction of the jaw appears to have been a common phenomenon. Syphilitic aneurism and neurosyphilis, on the other hand, were rarely observed. Gonorrhoea was widespread, particularly since patients were unwilling to undergo prolonged treatment; it was seen as an inevitable affliction which was limited in consequences. Chancroid was common. Some forms of vaginitis were sexually transmitted, and the condition was noted in medical treatises.

The most common treatment was sublimate of mercury. Preparations with arsphenamine such as salvarsan, or " 606 ", made rapid inroads during the $1910 \mathrm{~s}$, but they did not replace older methods; even neosalvarsan, or "914", only gradually took the place of mercury. Many new drugs, however, remained confined to the urban centres and were beyond the means of most people. Silver nitrate for the treatment of ophthalmia neonatorum, for instance, was rarely available even in the $1930 \mathrm{~s}^{12}$ High medical costs, the stigma attached to venereal infection and an aversion for prolonged treatment made people turn to quack doctors and traditional physicians. ${ }^{13}$ Advertisements for medicines against venereal disease followed upon the advent of the mass circulation newspaper in China in the early twentieth century. ${ }^{14}$ In Harbin, a city in the north of China with a population of 300,000 , two hundred self-proclaimed "hospitals" derived their main income from the employment of salvarsan or substitute solutions in $1927 . .^{15}$ Chinese and Western doctors were relentless in their attacks on charlatans and self-styled clinics. The need for the new medical science to win public and professional acceptance, the competition over the shifting allegiance of certain sectors of the public, the emergence of new norms of behaviour, the spread of general education and a better knowledge about the medical aspects of popular medicine are some of the reasons which underlay fears of quackery in the 1920 s and 30 s.

Until the advent of the Nationalist government in 1927, the lack of a central authority was the major obstacle in the prevention of STDs. A network of prophylactic institutes and dispensaries was never created, and official efforts in public education were minimal. Police regulations required a periodic inspection of all women in public houses, but no programme to reduce and regulate prostitution was set up until 1928. Although the
National Medical Association made a statement in March 1922 on the threat of venereal disease and the need for public information, no consistent anti-syphilitic policies were adopted by independent organisations. ${ }^{16}$ Official measures remained limited even after the unification of the country by the Nationalist government from 1927 to 1937 . Despite the creation of a Ministry of Health in 1928, public health authorities lacked the financial resources and the political will effectively to combat STDs; the regulation of prostitution was never genuinely implemented. ${ }^{17}$ Syphilology, a new field which spawned university chairs, societies and conferences in nineteenth century Europe, was not fully promoted to the rank of a medical discipline in Republican China. Even if public health was never high on the agenda of the Nationalist government, medical authorities had more urgent priorities than STDs. They were confronted with many other serious diseases such as cholera, smallpox, typhoid fever, tuberculosis and leprosy, which were rampant until the 1950s.

Public opinion, however, was mobilised by increasingly influential groups of social reformers. After a new era of "science" and "progress" was announced during the New Culture Movement (1915-1921), a burgeoning number of family handbooks, manuals on hygiene and treatises on physiology started to define new norms about and attitudes towards bodily cleanliness. Under the guise of science, these popular booklets liberally gave advice and offered precepts on hygiene, housekeeping, proper clothing, diet and related matters. They were written in simple language and served as a guide for the new social classes in the urban centres. Primary and secondary schools also became the centres for the dissemination of new knowledge about hygiene. Textbooks on medicine were printed to fit a new curriculum, and school teachers gave courses on the physiology of health. Improved medical understanding of venereal disease also spurred a growing number of social reformers and professional physicians into action. Treatises on the medical pathology of syphilis were published, handbooks on venereal disease proliferated and booklets on sex education appeared on the shelves during the $1920 \mathrm{~s}$ and $30 \mathrm{~s} .{ }^{18}$ The gruesome consequences of venereal disease on the individual, the family and the "race" were spelled out in harrowing detail by popular writers. In a context of foreign economic oppression and military presence, the spectre of general infection was raised: new notions about venereal diseases embodied social anxieties.

The relationship between syphilis and prostitution in particular became a favourite theme of the social reformers. Generically called "sex diseases" or "sexual maladies" (xingbing), the existence of venereal disease was thought to highlight the perils of sex and the corruption of the flesh. Syphilis, or "plum poison", was "transmitted" by a "carrier" in the market of venereal trade, the morbid gift for which the customer did not pay. Claims 
of social degeneration also flourished with the ascent of the idea of "race" in an era of rabid nationalism. ${ }^{19}$ Syphilis was seen as a cause of "racial decline". ${ }^{20}$ The idea of degeneration, encompassed in the powerful myth of hereditary syphilis, was criticised in Europe in the aftermath of the First World War, but a combination of nationalistic rhetoric and social hygiene contributed to perpetuate such social beliefs in China well into the 1940s. Eugenists added hereditary syphilitics to the list of "unfit elements" who should be prevented from marrying. ${ }^{21}$

Pollution was thought to have a foreign origin. Just as syphilis was construed as a foreign disease during the epidemic of the late fifteenth century in Europe (French pox for the English, the Neapolitan disease for the French), syphilis was described as a Western import by social improvers. Cultural representations of syphilis expressed the idea that China had been colonised by the dual forces of foreign capital and lethal disease. Imperialists "violated" the country's territorial integrity, germs "encroached" upon the urethra. Depicted as an alien evil which insinuated itself through the most intimate parts of the body, images of syphilis also reinforced stereotypes about foreign sexuality; writers rarely failed to mention that the ports frequented by foreign sailors were the most severely affected by the disease. Syphilis became the first version of the bacteriological warfare myth: engineered by imperialists, it was spread by soldiers as an instrument of death.

Sex education, promoted by social reformers, was a modern technique used to introduce new social norms to the urban classes. For Pan Gongzhan, one of the first intellectuals to take an active interest in "the science of sex", the physical degeneration and the moral dissolution of the "race" were the twin dangers of "modern civilization". ${ }^{22}$ In a period of transitional morals, sex education was thought to serve as a guide and preparation for marriage and a preventive of the dangers of venereal disease. Sex educators prescribed chastity before marriage, eugenic criteria in the choice of a marriage partner, the strict regulation of hereditary diseases and the elimination of deviant practices. A flourishing genre of literature on the health of married couples encouraged conjugal fidelity and the restriction of sexual relations. Women in particular were singled out as objects of increased solicitude; the husband took the disease home to his wife and children, introducing the germs from the public spheres of pleasure to the private sphere of domesticity: "The majority of the most common venereal diseases like syphilis and gonorrhoea are contracted when visiting prostitutes. After having been contaminated by this type of sexual disease, besides the harm inflicted to one's own body, one will also infect one's wife and genetically transmit the disease to one's children. The infection of offspring affects the health of the nation and the future of the race." ${ }^{23}$ The discovery in Europe during the last decades of the nineteenth century of venereal insontium, or infections of the innocent, had a particular impact in modern China. For social reformers who promoted the nuclear family as the only acceptable model for "modern" society, venereal disease was construed as a family poison brought home by sinful husbands. Tales of horror underlined the nefarious effects of syphilis upon pregnancy: after corruption of the seed, "some are born mute, some are born blind, some are born deaf, others have their skin peeled off, and some have all kinds of monstrous features". ${ }^{24}$ Medical literature was instrumental in the articulation of collective phobias. The idea that physiological gonorrhoea was the result of masturbation pervaded the literature dedicated to youth. Fears of easy contagion multiplied; an early communist handbook written before the communist victory in 1949 informed the reader that venereal diseases were caused by intercourse with prostitutes but could also be transmitted by handshakes and shared toiletry. ${ }^{25}$ Lowbrow handbooks on sex, on the other hand, dispensed practical advice on how to recognise the signs of infection in prostitutes. ${ }^{26}$

As in modern Europe, the general public remained relatively immune to the medical and literary stir. Cultural representations of venereal disease, however, were perpetuated by the communist party.

\section{COMMUNIST CHINA (1949-THE PRESENT)}

The control of STDs became a major political issue in the People's Republic of China (PRC). Urban prostitutes and ethnic minorities became the two main targets of an antisyphilitic campaign immediately after the communist victory in 1949. The Ministry of Health organised teams to investigate the epidemiological state of the nation and to work out strategies for the prevention and treatment of STDs; a Central Research Institute of Dermatology and Venereology was established in 1954. In addition to medical treatment, prostitutes were also given social and vocational rehabilitation. Mass campaigns against syphilis were extended during the next ten years to the rest of the population, including health education campaigns by means of lectures, plays, radio and small discussion groups. ${ }^{27}$ The use of penicillin greatly facilitated the treatment of syphilis, but social factors were also central to the control of disease. George Hatem, a Western physician who joined the communists in the 1930s, directed a campaign against venereal diseases in the PRC which was claimed to be very successful. ${ }^{28} \mathrm{He}$ described how during a first stage, the social and economic causes of prostitution were eliminated through a programme of social engineering. The second stage consisted of the serological screening and treatment of high-risk groups, selected by questionnaires and trainees. The rate of infection of the country was found to be $3,8 \%$, but China boasted that venereal disease had been completely eradicated in 1964, a statement 
which has generally been accepted unreservedly by foreign observers sympathetic to the communist regime. ${ }^{29}$ It is beyond reasonable doubt that the incidence of STDs was brought close to zero in the major urban centres, but reliable data which would allow the historian to give an accurate estimate of the success of communist mass campaigns over the long term are absent. The Cultural Revolution (1967-1975) in particular was a period of social disintegration during which the incidence of STDs may have risen markedly in certain regions. Venereology disappeared as a medical specialisation during the 1960s and the subject of STDs remained taboo until the State Council finally admitted in 1986 that venereal disease had resurfaced.

The crusade against the "rotten fruit of capitalism" was severe in the 1950 s, but authorities could not prevent the revival of prostitution throughout the 1980s: the number of hotels, hair salons, dormitories, underground brothels and even taxis involved in this lucrative trade soared, closely followed by an extension of prison camps for prostitutes. The revival of prostitution in mainland China since the reforms initiated by Deng Xiaoping after 1978 has contributed to the threat of STDs to public health. The total number of VD cases reported from 1980 through the end of 1988 was 140,648 , a number which may represent only a small proportion of the total incidence. A sex education programme was finally started in the mid-1980s, but the general tone remained cautious and demure. Collective fears about venereal infection became particularly virulent after the discovery of several cases of AIDS in 1989. Official discourse and popular prejudice explained AIDS as an evil from abroad, and prostitutes who offered their service to foreigners were singled out for severe punishment. ${ }^{30}$ This official line of thought elicited a law on the mandatory testing of all foreign residents, a bigoted approach which has nurtured intolerance and ignorance. Pollution from abroad remained an important part of modern communist rhetoric, and during the 1980 s, campaigns against bourgeois liberalism from the West had for target the "spiritual pollution" of citizens. Recent discoveries of larger numbers of AIDS cases in the southern province of Yunnan have compelled the government to accept that the virus is not only a foreign import. ${ }^{31}$ The spread of STDs is also due to legal sanctions and social pressure against homosexuals, who are forced to gather in unsanitary conditions. Considered a crime which should be eliminated or a mental illness which can be treated by electric shocks, homosexuality is met with summary arrest and long prison sentences.

As in China before 1949, STDs present a serious threat to public health. The responses which have been generated by venereal infection are also strikingly similar to those of the first half of the century; the debate about morality and medicine, the use of sex education to label and circumscribe social deviance, the emphasis on social control and the cultural fears about disease and contamination have all reappeared during the last few years. In this respect at least, recent developments in the People's Republic can be interpreted as a continuation of the cultural history of STDs in pre-revolutionary China.

1 Gulik RH van. Sexual Life in Ancient China, Leiden, Brill, 1974.

2 Henderson E. A report on prostitution in Shanghai; drawn up for 'The Council for the Foreign Community of up for 'The Council for
Shanghai', Shanghai, 1871.

3 Maxwell IL. 'Some notes on syphilis among the Chinese', China Medical fournal, 1913;27:379-86.

4 Lennox WG, 'Neurosyphilis among Chinese', China Medical fournal, 1923;37:663-71.

5 Korns JU. 'Further statistics on communicable diseases among domestic servants', China Medical fournal, 1921;35:382.

6 Faust EC. 'Social diseases in China', Social Pathology, 1925;6:274-7.

7 Wu LT. 'Problem of venereal diseases in China', China Medical fournal, 1927;41:28-36.

8 Lamson HD. Social Pathology in China, Shanghai, The Commercial Press, 1935. The missionary literature is also reviewed in Henriot C, 'Medicine, VD and prostitution in pre-revolutionary China', Social History of Medicine, 1992;5:95-120.

9 Frazier CN. 'The prevention and control of syphilis', China Medical fournal, 1937;51:1043-6.

10 Lai DG. 'Incidence of syphilis among the Chinese soldiers at Swatow', China Medical fournal, 1928;42:557-67; Lai DG and Suchen Wang Lai, 'Incidence of syphilis among Chinese civilian patients in Swatow district', China Medical fournal, 1929;43:22-27.

11 Heath FJ. 'Venereal diseases in relation to prostitution in China', Social pathology, 1925;6:278-84.

12 Gear HS. 'The incidence of venereal diseases in hospital patients in China', China Medical fournal, patients in $1935 ; 49: 1122-35$.

13 Heimburger LF. 'The incidence of syphilis at the Shantung Christian University dispensary', China Medical fournal, 1927;41:541-50.

14 Huang Kewu. 'Cong Shenbao yiyao guangbao kan minchu de yiliao wenhua yu shehui shenghuo, 1912-1926' (Medical culture and social life in the early Republican era as seen through the medical advertisements of the Shenbao, 1912-1926), Zhongyang yanjiuyuan jindaish yanjiusuo jikan, 1988;17:141-94.

15 Wu LT. 'Problem of venereal diseases in China', China Medical fournal, 1927;41:34.

16 Peter WW. 'Fighting venereal disease openly', Chine Medical fournal, 1924;35:1-29.

17 Wang Shunu. Zhongguo changii shi (The history of prostitution in China), Shanghai, Shanghai sanlian shudian, tion in China),

18 Dikötter F. Sex, Culture and Society in Modern China, London, C Hurst.

19 Dikötter F. The Discourse of Race in Modern China, London, C Hurst, Stanford, Stanford University Press, 1992.

20 Jian Meng. 'Meidu shi zhongzu shuaitui de yuanyin' (Syphilis is the cause of racial decline), Dongfang zazhi, 1922;19:85-6.

21 Dikötter F. 'Eugenics in Republican China', Republican China, 1989;5:1-18.

22 Pan Gongzhan. 'Liangxing jiaoyu' (Sex education for men and women), fiaoyu zazhi, 1921, 12.

23 Fan Shouyuan. Qingnian weisheng jianghua (Guide to hygiene for youth), Shanghai, Zhengzhong shuju, 1947, 44.

24 Cheng Hao. Fiezhi shengyu wenti (Questions about birth control), Shanghai, Yadong tushuguan, 1925, p. 92.

25 Chen Shu. Xingbing changshi (Elementary knowledge of venereal diseases), Harbin, Guanghua shudian, 1948.

$26 \mathrm{Xu}$ Zheshen. Xingfang mijue (Secrets of the bedchamber), Shanghai, Xinxin shudian, 1938, 89-91.

27 Worth RM. 'New China's accomplishments in the contro of diseases'. In: ME Wegman, TY Lin, EF Purcell (eds), Public Health in the People's Republic of China, New York, Josiah Macy, 1973, 176-8; Hu, CK et al., The control of veneral diseases in new China' Chinese Medical fournal, 1953;71:248-58; Huang KY, 'Medical fournal, 1953;71:248-58; Huang KY, Medicine and Public Health in the People's Republic of Medicine and Public Health in the People's

28 Hatem G. 'With Mao Tse-tung's thought as the compass for action in the control of venereal diseases in China', for action in the control of venereal diseases in China', Other Side of the River, New York, Random House, Other Side of the River, New York, Random House,
1961 , and Snow E, Red China Today, New York, 1961, and Snow E, Red China Today, New York, Vintage Books, 1970, 261-3.

29 Horn JS. Away with All Pests, London, Paul Hamlyn, 1969.

30 Ruan FF. Sex in China: Studies in Sexology in Chinese Culture, New York, Plenum Press, 1991.

31 Chen Fan. Xingbing zai Zhongguo (Venereal diseases in China), Beijing, Shiyueyi chubanshe, 1990 